\title{
Efficient Ru-Fe catalyzed selective hydrogenolysis of carboxylic acids to alcoholic chemicals $\uparrow$
}

Cite this: RSC Adv., 2014, 4, 29072

\author{
Wenjing Li, ${ }^{a}$ Linmin Ye, ${ }^{a}$ Pei Long, ${ }^{a}$ Jin Chen, ${ }^{a}$ Hiroko Ariga, ${ }^{b}$ Kiyotaka Asakura ${ }^{b}$ \\ and Youzhu Yuan*a
}

Supported bimetallic Ru-Fe catalysts were prepared using a step-deposition-reduction method. The selective hydrogenolysis of acetic acid to ethanol was investigated as a reaction, which is considered to be related to the transformation of biomass-derived carboxylic acids to fuels and value-added chemicals. An SBA-15-supported Ru-Fe catalyst displayed significant improvements in catalytic performance for the hydrogenolysis of acetic acid to ethanol compared with monometallic catalysts and that with $\mathrm{SiO}_{2}$ as a carrier. When the Ru/Fe atomic ratio was set at 2/1, the prepared catalyst could give a nearly $100 \%$ conversion of acetic acid and $88 \%$ selectivity to ethanol. The catalyst showed considerable stability in terms of structure and performance for a long-term run on stream. Characterization results indicated that a small portion of Fe species was alloyed with $\mathrm{Ru}$, whereas the other portion of Fe species, likely $\mathrm{FeO}_{1+x}(0<x<0.5)$, was dispersed on the catalyst surfaces. The Fe species were crucial for the stabilization of $\mathrm{Ru}-\mathrm{Fe}$ bimetallic nanoparticles and activation of acetic acid molecules in the hydrogenolysis reaction. Moreover, several other carboxylic acids, such as propionic acid, levulinic acid, and lactic acid, could also be efficiently converted to their corresponding alcoholic chemicals or lactone using the optimized Ru-Fe/SBA-15 catalyst under relatively mild conditions.

Received 9th April 2014

Accepted 19th June 2014

DOI: $10.1039 / c 4 r a 03201 b$

www.rsc.org/advances
Alcohols can further be converted to alkanes with minor losses of energy. In contrast to the very simple but seriously disadvantageous thermochemical pathway of pyrolysis, a more efficient novel way has recently been suggested through carboxylate platforms for the production of biofuels and biochemical from biomass. $^{2,3}$ In fact, the transformation of lignocellulose to fuel EtOH follows an indirect route involving the fermentation of lignocellulose to acetic acid $(\mathrm{AcOH})$ and hydrogenolysis of $\mathrm{AcOH}$, or direct hydrogenolysis or fermentation of sugars and glucose, or conversion of syngas derived from biomass gasification..$^{3-7}$ However, the hydrogenolysis of sugars and conversion of biomass-derived syngas only produces low yields of EtOH. ${ }^{5-7}$ Compared with the direct fermentation of glucose to $\mathrm{EtOH}$ (Reaction (1)), the fermentation of glucose to $\mathrm{AcOH}$ followed by the hydrogenolysis of $\mathrm{AcOH}$ to $\mathrm{EtOH}$ can prevent the emission of $\mathrm{CO}_{2}$ (Reaction (2)), achieving $100 \%$ carbon yield which against $48 \% \mathrm{CO}_{2}$ produced in Reaction (1). ${ }^{8}$ Thus, the hydrogenolysis of $\mathrm{AcOH}$ may be considered as an efficient route that bridges the gap between biomass and fuel $\mathrm{EtOH}$ in view of atom economy.

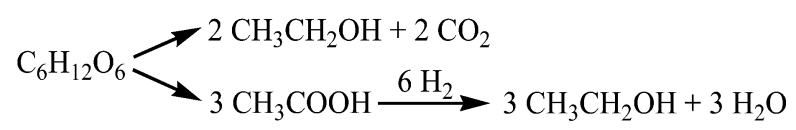

On the other hand, the hydrogenolysis of carboxylic functional group is the crucial reaction for the production of alcohol from the biomass-derived feedstock. ${ }^{9}$ The development of 
low-cost, high-efficiency hydrogenolysis routes will open economically viable pathways from renewable resource-derived materials as alternatives to fossil-based chemicals. ${ }^{\mathbf{1 0}, 11}$ Also, the reaction is one of the most useful synthetic tools in the transformation of fats, in particular the synthesis of fatty alcohols from their corresponding carboxylic acids and esters. ${ }^{12,13}$ Fatty alcohols are nonionic surfactants and are widely used in lubricants, resins, perfumes, cosmetics, shampoos and conditioners. ${ }^{14}$ Recently, fatty alcohols have been explored for potential use in medicine, health supplements and biofuels. ${ }^{15}$

However, the hydrogenolysis of short chain carboxylic acids to alcohol in a continuous flow system working in vapor phase under mild conditions seems to be still a problematic step. Further, hydrogenolysis of the $\mathrm{C}-\mathrm{C}$ bond and over hydrogenation of alcohols may also occur, resulting in cracked products and alkanes, respectively. ${ }^{\mathbf{1 6 - 1 8}}$ The reaction indicates that promoting $\mathrm{C}-\mathrm{O}$ bond breakage and hydrogenating $\mathrm{C}=\mathrm{O}$ bond but suppressing $\mathrm{C}-\mathrm{C}$ bond cleavage of carboxylic acids will result in high selectivity toward the corresponding alcohols. $\mathrm{AcOH}$ can be the model to test the carboxylic acid adsorption and its conversion kinetics because of molecular simplicity and wide range commercial application. Noble metals, such as $\mathrm{Pt}$ and Ru-based catalysts, have been intensively explored for the hydrogenolysis reaction of carboxylic acids. ${ }^{16-21}$ Several researchers have studied the effects of a second metal on the catalysts to improve the activity and selectivity of noble catalysts. For example, Jiang et al. reported that the introduction of $\mathrm{Cu}$ to $\mathrm{Ru}$-based catalysts could improve $\mathrm{C}-\mathrm{O}$ cleavage and suppress $\mathrm{C}-\mathrm{C}$ cleavage. ${ }^{22}$ Miyake et al. revealed that the addition of appropriate amount of $\mathrm{Sn}$ to $\mathrm{Ru}$-based catalysts promoted both catalytic activity and selectivity in the hydrogenation of fatty acid methyl esters to alcohols. ${ }^{23}$ Toba et al. reported that $\mathrm{Ru}-\mathrm{Sn} / \mathrm{Al}_{2} \mathrm{O}_{3}$ catalysts demonstrated good yields in the hydrogenolysis of saturated carboxylic acids to their corresponding alcohols, ${ }^{24}$ but the reported technique required high pressure and temperature.

Ordered mesoporous materials based silicas like MCM-41, SBA-15, and HMS with tunable and regular mesopores, easily accessible internal surface, and relatively high surface areas have been extensively used as carriers for preparing supported metal catalysts. As a result of its large specific surface area, uniform pore size distribution, and better thermal and hydrothermal stability, the catalysts thus prepared are promising for many catalytic reactions in which hydrogen is required, such as photocatalysis, hydrogenation, oxidative dehydrogenation, hydrodesulfurization, and the Fischer-Tropsch synthesis. ${ }^{25-28}$

In this work, Fe-doped Ru/SBA-15 catalysts (Ru-Fe/SBA-15) prepared by a step-deposition-reduction (SDR) method showed remarkable activity and selectivity for the hydrogenolysis of several bio-derived carboxylic acids, such as $\mathrm{AcOH}$, propionic acid, levulinic acid, butyric acid, and lactic acid to their corresponding alcohols. The catalyst structure was characterized by $\mathrm{X}$-ray fluorescence (XRF), $\mathrm{N}_{2}$ adsorption-desorption isotherms, $\mathrm{X}$-ray diffraction (XRD), $\mathrm{H}_{2}$-temperature-programmed reduction $\left(\mathrm{H}_{2}\right.$-TPR), AcOH-temperature programmed desorption ( $\mathrm{AcOH}-$ TPD), transmission electron microscopy (TEM), and X-ray photoelectron spectroscopy (XPS). The relationship between the structure and performance of the bimetallic $\mathrm{Ru}-\mathrm{Fe} / \mathrm{SBA}-15$ catalysts was further elucidated.

\section{Results and discussion}

\subsection{Effects of $\mathrm{Ru} / \mathrm{Fe}$ atomic ratio}

The catalysts with different $\mathrm{Ru} / \mathrm{Fe}$ atomic ratios supported on SBA-15 were tested for the hydrogenolysis of AcOH into EtOH at $493 \mathrm{~K}$ (Table 1). The reaction yielded products of EtOH, acetaldehyde (AH), ethyl acetate (EtOAc), acetone, and gases (including methane, ethane, and $\mathrm{CO}_{x}$ ). The monometallic catalyst $5 \% \mathrm{Ru} / \mathrm{SBA}-15$ gave a reasonable $\mathrm{AcOH}$ conversion of $15.5 \%$ and $74.5 \%$ selectivity to methane, indicating that the monometallic $\mathrm{Ru}$ catalyst could break the $\mathrm{C}-\mathrm{C}$ bond in $\mathrm{AcOH}$. The $5 \% \mathrm{Fe} / \mathrm{SBA}-15$ catalyst had a very low $\mathrm{AcOH}$ conversion of $1.3 \%$ with $33.1 \%$ of selectivity to acetone. However, the Ru-Fe bimetallic catalysts displayed a distinct catalytic performance. When a small amount of Fe was added into $\mathrm{Ru} / \mathrm{SBA}-15$ with a $\mathrm{Ru} / \mathrm{Fe}$ atomic ratio at $15 / 1$, the conversion of $\mathrm{AcOH}$ was increased to $35.8 \%$ with a $66.8 \%$ selectivity to EtOH. The $\mathrm{AcOH}$ conversion and EtOH selectivity were gradually increased when the Fe content was further increased. For $5 \% \mathrm{Ru}_{3}-\mathrm{Fe}_{1} / \mathrm{SBA}-15$ as an example, the $\mathrm{AcOH}$ conversion increased to $44.0 \%$ with $75.2 \%$ EtOH selectivity. The $\mathrm{AcOH}$ conversion approached a maximal value of $57.2 \%$ with a $67.0 \%$ selectivity to $\mathrm{EtOH}$ when the Fe content was promoted to a $\mathrm{Ru} / \mathrm{Fe}$ atomic ratio of $2 / 1$. After that, further increase of Fe content caused decreases both in $\mathrm{AcOH}$ conversion and EtOH selectivity. The $\mathrm{AcOH}$ conversion and EtOH selectivity dropped to $21.7 \%$ and $64.9 \%$ over the $5 \%$ $\mathrm{Ru}_{1}-\mathrm{Fe}_{1} / \mathrm{SBA}-15$ catalyst, respectively. When the reaction temperature was increased to $533 \mathrm{~K}$, similar trends for the $\mathrm{AcOH}$ conversion and EtOH selectivity were observed over the catalysts with different $\mathrm{Ru} / \mathrm{Fe}$ atomic ratios (Table $2 \mathrm{~S}$, ESI $\dagger$ ). We found that the highest EtOH yield could be obtained over the $5 \% \mathrm{Ru}_{2}-$ $\mathrm{Fe}_{1} / \mathrm{SBA}-15$ catalyst, although the $\mathrm{Ru}_{10}-\mathrm{Fe}_{1}$ and $\mathrm{Ru}_{2}-\mathrm{Fe}_{1}$ catalysts performed similar catalytic performance at this temperature.

Furthermore, the catalytic activity of the Ru-Fe/SBA-15 bimetallic catalysts underwent a volcano-like tendency with $\mathrm{Fe}$ content. The turnover frequency (TOF) was obtained by controlling the AcOH conversion below 30\%. A maximum TOF of $1957.8 \mathrm{~h}^{-1}$ was achieved by the $\mathrm{Ru}_{2}-\mathrm{Fe}_{1} / \mathrm{SBA}-15$ catalyst, which was higher than those obtained with monometallic $\mathrm{Ru}$ catalysts in present work and in literature (at $518 \mathrm{~K}) .{ }^{29}$ The result indicated that the doped Fe species resulted in a clear promotional effect on the $\mathrm{AcOH}$ hydrogenolysis.

\subsection{Effects of preparation method and support}

The factors affecting the preparation of catalysts, including preparation method and material, had a significant influence on the catalytic performance (Tables 1 and 2). By fixing the $\mathrm{Ru}$ / Fe atomic ratio, the $5 \% \mathrm{Ru}_{2}-\mathrm{Fe}_{1} / \mathrm{SBA}-15-\mathrm{CoIm}-773 \mathrm{~K}$ catalyst prepared by co-impregnation and calcined at $773 \mathrm{~K}$ yielded a $24.0 \%$ conversion of $\mathrm{AcOH}$ and $63.5 \%$ selectivity to EtOH at $493 \mathrm{~K}$, whereas the $5 \% \mathrm{Ru}_{2}-\mathrm{Fe}_{1} / \mathrm{SBA}-15-\mathrm{CoIm}-573 \mathrm{~K}$ catalyst prepared by co-impregnation and calcined at $573 \mathrm{~K}$ yielded a 
Table 1 Catalytic performance of supported $5 \% \mathrm{Ru}_{x}-\mathrm{Fe}_{y}$ catalysts for $\mathrm{AcOH}$ hydrogenolysis ${ }^{a}$

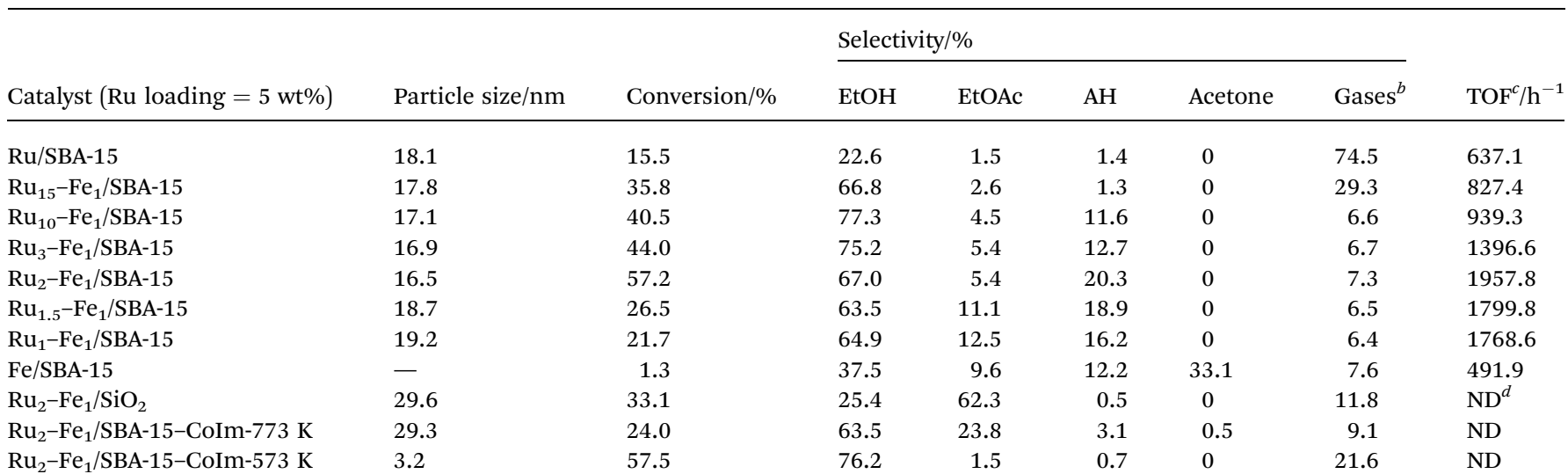

${ }^{a}$ Reaction conditions: catalyst weight $=0.20 \mathrm{~g}, T=493 \mathrm{~K}, P\left(\mathrm{H}_{2}\right)=3.0 \mathrm{MPa}, \mathrm{LHSV}_{(\mathrm{AcOH})}=1.5 \mathrm{~h}^{-1}, \mathrm{H}_{2} /$ acid $=80 .{ }^{b}$ Gases include methane, ethane, and $\mathrm{CO}_{x}{ }^{c}$ TOF was obtained by keeping AcOH conversion below $30 \%$ (see Table 1S, ESI for details) and using the data of metal dispersion from $\mathrm{H}_{2}$ adsorption. ${ }^{d}$ ND: not detected.

Table 2 Catalytic performance of supported $5 \% \mathrm{Ru}_{x}-\mathrm{Fe}_{y}$ catalysts with different supports for AcOH hydrogenolysis ${ }^{a}$

\begin{tabular}{|c|c|c|c|c|c|c|}
\hline \multirow[b]{2}{*}{ Catalyst (Ru loading $=5 \mathrm{wt} \%$ ) } & \multirow[b]{2}{*}{ Conversion $/ \%$} & \multicolumn{5}{|c|}{ Selectivity/\% } \\
\hline & & $\mathrm{EtOH}$ & EtOAc & $\mathrm{AH}$ & Acetone & Gases $^{b}$ \\
\hline $\mathrm{Ru}_{2}-\mathrm{Fe}_{1} / \mathrm{SBA}-15$ & 57.2 & 67.0 & 5.4 & 20.3 & 0 & 7.3 \\
\hline $\mathrm{Ru}_{2}-\mathrm{Fe}_{1} / \mathrm{ZSM}-5(\mathrm{Si} / \mathrm{Al}=50)$ & 32.9 & 64.6 & 26.6 & 1.2 & 1.4 & 6.2 \\
\hline $\mathrm{Ru}_{2}-\mathrm{Fe}_{1} / \mathrm{ZSM}-5(\mathrm{Si} / \mathrm{Al}=25)$ & 22.5 & 54.9 & 37.4 & 0.6 & 1.1 & 6.0 \\
\hline $\mathrm{Ru}_{2}-\mathrm{Fe}_{1} / \mathrm{HY}(\mathrm{Si} / \mathrm{Al}=30)$ & 15.9 & 19.7 & 66.6 & 0.3 & 0 & 13.3 \\
\hline $\mathrm{Ru}_{2}-\mathrm{Fe}_{1} / \mathrm{SiO}_{2}$ & 33.1 & 25.4 & 62.3 & 0.5 & 0 & 11.8 \\
\hline $\mathrm{Ru}_{2}-\mathrm{Fe}_{1} / \mathrm{Al}_{2} \mathrm{O}_{3}$ & 32.9 & 76.4 & 3.6 & 0.9 & 0.2 & 18.9 \\
\hline
\end{tabular}

${ }^{a}$ Reaction conditions: catalyst weight $=0.20 \mathrm{~g}, P\left(\mathrm{H}_{2}\right)=3.0 \mathrm{MPa}, T=493 \mathrm{~K}, \mathrm{LHSV}_{(\mathrm{AcOH})}=1.5 \mathrm{~h}^{-1}, \mathrm{H}_{2} /$ acid $=80 .{ }^{b}$ Gases include methane, ethane, and $\mathrm{CO}_{\mathrm{x}}$.

57.5\% AcOH conversion and $76.2 \%$ selectivity to EtOH. The conversion was $68.5 \%$ with $67.8 \%$ EtOH selectivity over $5 \%$ $\mathrm{Ru}_{2}-\mathrm{Fe}_{1} / \mathrm{SBA}-15-\mathrm{CoIm}-773 \mathrm{~K}$ at $533 \mathrm{~K}$. For $5 \% \mathrm{Ru}_{2}-\mathrm{Fe}_{1} / \mathrm{SBA}-$ 15-CoIm-573 K catalyst, AcOH conversion was up to $99.9 \%$ with $99.7 \%$ selectivity to gas-phase products (including methane, ethane, and $\mathrm{CO}_{x}$ ) as the temperature increased to 533 K (Fig. 2S, ESI $\dagger$ ).

By replacing SBA-15 with other supports like ZSM-5, HY, $\mathrm{SiO}_{2}$ and $\mathrm{Al}_{2} \mathrm{O}_{3}$, the catalysts obtained displayed significantly different catalytic behaviours, giving a lower $\mathrm{AcOH}$ conversion in general (Table 2). The conversion of $\mathrm{AcOH}$ was $57.2 \%$ with $67.0 \%$ selectivity to EtOH over $5 \% \mathrm{Ru}_{2}-\mathrm{Fe}_{1} / \mathrm{SBA}-15$ at $493 \mathrm{~K}$. As for the $5 \% \mathrm{Ru}_{2}-\mathrm{Fe}_{1} / \mathrm{ZSM}-5(\mathrm{Si} / \mathrm{Al}=50)$ catalyst, the $\mathrm{AcOH}$ conversion was $32.9 \%$ with $64.6 \%$ selectivity to EtOH, while the $5 \% \mathrm{Ru}_{2}-\mathrm{Fe}_{1} / \mathrm{ZSM}-5(\mathrm{Si} / \mathrm{Al}=25)$ catalyst displayed a $22.5 \% \mathrm{AcOH}$ conversion with $54.9 \%$ selectivity to EtOH. The $5 \% \mathrm{Ru}_{2}-\mathrm{Fe}_{1} / \mathrm{HY}$ yielded a $15.9 \%$ AcOH conversion with $19.7 \%$ EtOH selectivity and $66.6 \%$ EtOAc selectivity. All the catalysts with aluminosilicate zeolites as supports produced considerable EtOAc. The 5\% $\mathrm{Ru}_{2}-\mathrm{Fe}_{1} / \mathrm{SiO}_{2}$ catalyst yielded a $33.1 \%$ conversion of $\mathrm{AcOH}$ with low selectivity to EtOH (25.4\%), but the $5 \% \mathrm{Ru}_{2}-\mathrm{Fe}_{1} / \mathrm{Al}_{2} \mathrm{O}_{3}$ catalyst gave a similar AcOH conversion (32.9\%) and reasonable EtOH selectivity (76.4\%). When the temperature increased to $533 \mathrm{~K}, \mathrm{AcOH}$ conversion increased but with a higher selectivity to gas-phase products (Fig. 3S, ESI $\dagger$ ). The above results suggest that the catalyst performance might have some relationship with the acid-base property of the catalyst supports.

\subsection{Effect of reaction temperature}

The temperature effects on the hydrogenolysis of $\mathrm{AcOH}$ were studied by choosing two typical catalysts, namely, $5 \% \mathrm{Ru}_{2}-\mathrm{Fe}_{1} /$ SBA-15 and $5 \% \mathrm{Ru}_{2}-\mathrm{Fe}_{1} / \mathrm{SBA}-15-\mathrm{CoIm}-573 \mathrm{~K}$. With the $5 \% \mathrm{Ru}_{2}-$ $\mathrm{Fe}_{1} / \mathrm{SBA}-15$ catalyst, the conversion of $\mathrm{AcOH}$ and selectivity to EtOH gradually increased as a function of reaction temperature and nearly reached $100 \% \mathrm{AcOH}$ conversion and $88 \%$ selectivity to EtOH at $543 \mathrm{~K}$ (Fig. 1). A further increase in the temperature caused a decrease in EtOH selectivity and an increase in gasphase products (data not shown). With the $5 \% \mathrm{Ru}_{2}-\mathrm{Fe}_{1} / \mathrm{SBA}-15-$ CoIm-573 K catalyst, a sharp increase in AcOH conversion was obtained when the reaction temperature increased, but the selectivity to EtOH clearly decreased, accompanying a large amount of gas-phase products.

\subsection{Hydrogenolysis of several carboxylic acids}

Substrates like propionic acid, levulinic acid, butyric acid, and lactic acid were chosen to determine the performance of the optimized $5 \% \mathrm{Ru}_{2}-\mathrm{Fe}_{1} / \mathrm{SBA}-15$ catalyst for the hydrogenolysis of 


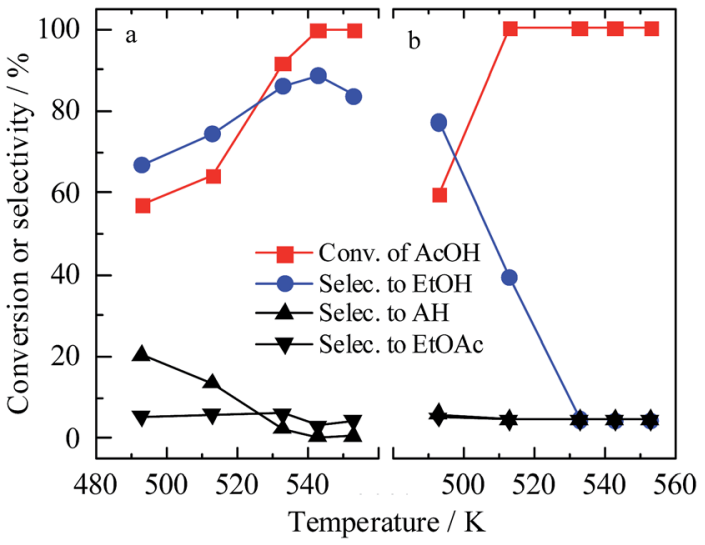

Fig. 1 Catalytic performance of $5 \% \quad \mathrm{Ru}_{2}-\mathrm{Fe}_{1} / \mathrm{SBA}-15$ catalysts prepared by different methods: (a) catalyst prepared by SDR method and (b) catalyst prepared by co-impregnation method.

carboxylic acids, except for AcOH (Table 3). The results show an $83.4 \%$ conversion of propionic acid and $82.5 \%$ selectivity to propanol under conditions similar to the hydrogenolysis of $\mathrm{AcOH}$. In the case of hydrogenolysis of butyric acid, $82.2 \%$ conversion was obtained with $85.1 \%$ selectivity to butanol. When the $5 \% \mathrm{Ru}_{2}-\mathrm{Fe}_{1} / \mathrm{SBA}-15$ catalyst was used for the hydrogenolysis of lactic acid in aqueous phase, an $80.8 \%$ conversion with $76.7 \%$ selectivity to 1,2-propandiol as the main product was obtained. The by-products 1-propanol, 2-propanol, and 1,3propandiol were derived from further hydrogenation or isomerization. For the hydrogenolysis of levulinic acid, a conversion of $85.1 \%$ and $85.8 \%$ selectivity to $\gamma$-valerolactone were obtained. In this case, the $\mathrm{C}=\mathrm{O}$ group was hydrogenated instead of - $\mathrm{COOH}$ in levulinic acid possibly because of very low hydrogen pressure $(0.75 \mathrm{MPa})$, and the $-\mathrm{OH}$ group generated from $\mathrm{C}=\mathrm{O}$ was esterified with-COOH. When the pressure was increased to 3.0 $\mathrm{MPa}$, the conversion of levulinic acid was up to $95.5 \%$ with $53.7 \%$ of selectivity to methyltetrahydrofuran (MTHF) which is a product of intramolecular cyclization of 2,5-pentandiol. The results show that the $\mathrm{Ru}-\mathrm{Fe}$ bimetallic catalyst could perform hydrogenolysis of various carboxylic acids to their corresponding alcoholic chemicals.

\subsection{Catalyst stability}

The long-term catalytic behaviour of $5 \% \mathrm{Ru}_{2}-\mathrm{Fe}_{1} / \mathrm{SBA}-15$ was investigated under optimized conditions, and the results are

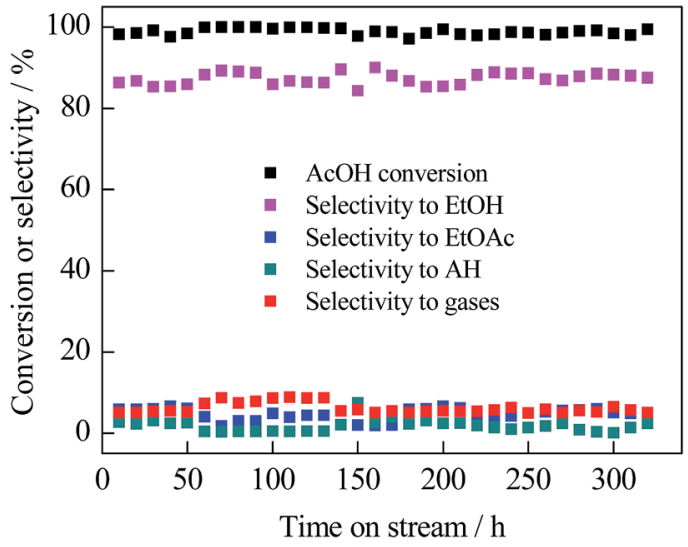

Fig. 2 Catalytic performance of $5 \% \mathrm{Ru}_{2}-\mathrm{Fe}_{1} / \mathrm{SBA}-15$ catalyst under the reaction conditions of $T=543 \mathrm{~K}, P\left(\mathrm{H}_{2}\right)=3.0 \mathrm{MPa}$, $\mathrm{LHSV}_{(\mathrm{AcOH})}=1.5$ $\mathrm{h}^{-1}$, and $\mathrm{H}_{2} / \mathrm{AcOH}=80$.

shown in Fig. 2. Almost $100 \%$ conversion of AcOH was achieved and the selectivity toward EtOH remained about $85 \%$ without significant changes for over $300 \mathrm{~h}$. No obvious aggregation of bimetallic particle size and structural collapse of the catalyst occurred after the reaction for $300 \mathrm{~h}$, as proven by the XRD patterns and TEM image (Fig. 1S and 2S, ESI $\dagger$ ).

\subsection{XRF and XRD}

The XRF results show that the actual loading amount and $\mathrm{Ru}$ / Fe ratios in the monometallic and bimetallic catalysts were highly similar to the theoretical values (Table 4). The XRD patterns of the as-reduced $5 \% \mathrm{Ru}_{x}-\mathrm{Fe}_{y} / \mathrm{SBA}-15$ catalysts with different $\mathrm{Ru} / \mathrm{Fe}$ atomic ratios are shown in Fig. 3 . The three characteristic peaks at low angles were assigned to the hexagonal mesoporous structure of SBA-15. Bimetal loading of $5 \% \mathrm{Ru}_{2}-\mathrm{Fe}_{1} / \mathrm{SBA}-15$ had no effect on the uniform structure based on the absence of changes at low angles (Fig. 2S, ESI $\dagger$ ). Several sharp peaks of monometallic Ru/SBA-15 at $38.4^{\circ}, 42.1^{\circ}$, $44.0^{\circ}, 58.3^{\circ}, 69.3^{\circ}, 78.3^{\circ}$, and $84.6^{\circ}$ were assigned to metallic Ru (100), (002), (101), (102), (110), (103), and (112), respectively. Moreover, the addition of $\mathrm{Fe}$ into Ru-based catalysts with different $\mathrm{Ru} / \mathrm{Fe}$ atomic ratios had no significant effects on peak position and intensity. Monometallic 5\% Fe/SBA-15 did not exhibit any characteristic peaks in XRD patterns, indicating a high dispersion of Fe species on SBA-15. However, only three characteristic peaks were observed according to the

Table 3 Hydrogenation of several acids using $5 \% \mathrm{Ru}_{2}-\mathrm{Fe}_{1} / \mathrm{SBA}-15$ catalyst

\begin{tabular}{|c|c|c|c|c|c|c|}
\hline Substrate & Temperature/K & Pressure/MPa & Conversion/\% & Selectivity $^{a} / \%$ & & \\
\hline Propionic acid & 533 & 3.0 & 83.4 & 82.5 (propanol) & 13.1 (propane) & 4.4 (others) \\
\hline Butyric acid & 533 & 3.0 & 82.2 & 85.1 (butanol) & 12.4 (butane) & 2.5 (others) \\
\hline Levulinic acid & 523 & 0.75 & 85.1 & $85.8(\mathrm{GVL})$ & $3.5($ pentanol $)$ & 10.7 (others) \\
\hline Levulinic acid & 543 & 3.0 & 95.5 & 53.7 (MTHF) & 27.5 (pentanol) & 18.8 (others) \\
\hline 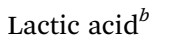 & 473 & 3.0 & 80.8 & 76.7 (1,2-PDO) & $13.4(1,3-\mathrm{PDO})$ & 9.9 (others) \\
\hline
\end{tabular}

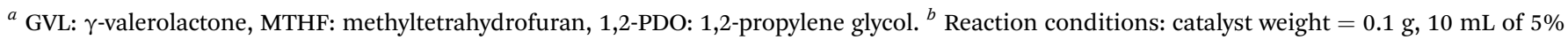
lactic acid aqueous solution was poured into a $50 \mathrm{~mL}$ steel autoclave. 
Table 4 Physicochemical properties of $5 \% \mathrm{Ru}_{x}-\mathrm{Fe}_{y} / \mathrm{SBA}-15$ catalysts

\begin{tabular}{|c|c|c|c|c|c|c|c|}
\hline \multirow[b]{2}{*}{ Catalyst } & \multirow[b]{2}{*}{$M_{\mathrm{Ru}+\mathrm{Fe}}{ }^{a} / \mathrm{wt} \%$} & \multirow[b]{2}{*}{$S_{\mathrm{BET}} / \mathrm{m}^{2} \mathrm{~g}^{-1}$} & \multirow[b]{2}{*}{$V_{\text {pore }}{ }^{b} / \mathrm{cm}^{3} \mathrm{~g}^{-1}$} & \multirow[b]{2}{*}{$D_{\text {pore }} / \mathrm{nm}$} & \multicolumn{2}{|c|}{$\begin{array}{l}\text { Average metallic size/ } \\
\mathrm{nm}\end{array}$} & \multirow[b]{2}{*}{$\mathrm{H}_{2}$-chemisorption $/ \mathrm{cm}^{3} \mathrm{~g}^{-1}$} \\
\hline & & & & & By $\mathrm{XRD}^{c}$ & By TEM & \\
\hline SBA-15 & - & 661.2 & 0.87 & 5.5 & - & - & 0 \\
\hline $\mathrm{Ru} / \mathrm{SBA}-15$ & 5.0 & 390.4 & 0.58 & 6.0 & 17.9 & 18.1 & 0.016 \\
\hline $\mathrm{Ru}_{15}-\mathrm{Fe}_{1} / \mathrm{SBA}-15$ & $5.0(13.2 / 1)$ & 357.2 & 0.56 & 6.0 & 17.5 & 17.8 & 0.084 \\
\hline $\mathrm{Ru}_{1.5}-\mathrm{Fe}_{1} / \mathrm{SBA}-15$ & $6.6(1.5 / 1)$ & 388.3 & 0.52 & 5.1 & 18.9 & 18.7 & 0.064 \\
\hline $\mathrm{Ru}_{1}-\mathrm{Fe}_{1} / \mathrm{SBA}-15$ & $7.6(0.9 / 1)$ & 348.4 & 0.54 & 5.9 & 19.6 & 19.2 & 0.031 \\
\hline Fe/SBA-15 & 5.2 & 548.7 & 0.62 & 5.4 & - & - & 0 \\
\hline
\end{tabular}

${ }^{a}$ Determined by XRF; data in parentheses represent the atomic ratios of Ru/Fe. ${ }^{b}$ Obtained from $P / P_{0}=0.99 .{ }^{c}$ Calculated by the Scherrer equation.

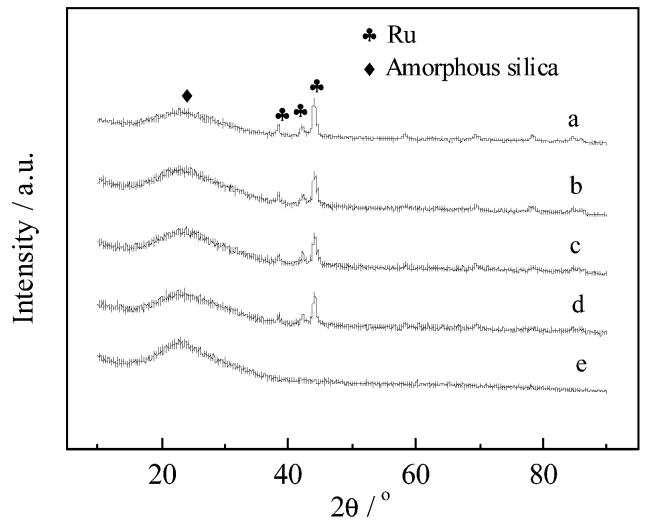

Fig. 3 XRD patterns of as-reduced $5 \% \mathrm{Ru}_{x}-\mathrm{Fe}_{y} / \mathrm{SBA}-15$ catalysts with different Ru/Fe atomic ratios: (a) Ru/SBA-15; (b) $\mathrm{Ru}_{10}-\mathrm{Fe}_{1} / \mathrm{SBA}-15$; (c) $\mathrm{Ru}_{2}-\mathrm{Fe}_{1} / \mathrm{SBA}-15$; (d) $\mathrm{Ru}_{1}-\mathrm{Fe}_{1} / \mathrm{SBA}-15$; and (e) Fe/SBA-15.

standard powder XRD data of Fe, and the sharpest peak at $44.6^{\circ}$ was close to that of Ru (Fig. 3S, ESI $\dagger$ ). Thus, the possible existence of $\mathrm{Ru}-\mathrm{Fe}$ alloy could not be distinguished based on the presence of a shift in the peak. A similar particle size around $17 \mathrm{~nm}$ in the prepared bimetallic catalysts was obtained by the Scherrer equation using the value of half bandwidth in the intensive peak at $44.0^{\circ}$, which agreed with the results of metallic particle size distributions (Fig. 4S, ESI†). Both data were incorporated in Table 4.

\section{7. $\mathrm{H}_{2}$-TPR}

As shown in Fig. 4, the reduction behaviour of metal oxide was characterized by $\mathrm{H}_{2}$-TPR and $\mathrm{H}_{2}$ consumption was detected by mass spectrometer $(m / z=2)$. Compared with SBA-15, two peaks appeared at 445 and $570 \mathrm{~K}$ in the TPR curve of the as-calcined $5 \% \mathrm{Ru} / \mathrm{SBA}-15$ sample. The main peak at $445 \mathrm{~K}$ was recognized as the reduction of $\mathrm{Ru}^{4+}$ to $\mathrm{Ru}^{0}{ }^{30}$ and the small peak at $565 \mathrm{~K}$ was assigned to the reduction of valent Ru species that strongly interacted with the support, indicating that the Ru oxide was completely reduced to metal $\mathrm{Ru}$ after reduction at $623 \mathrm{~K}$. An elevated temperature is needed to reduce Fe oxides, and the peaks at 680 and $840 \mathrm{~K}$ are attributed to the reduction of $\mathrm{Fe}^{3+}$ to

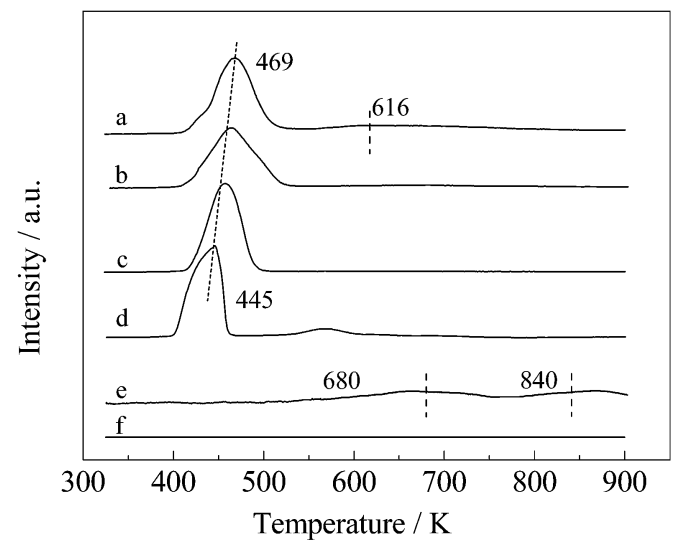

Fig. $4 \mathrm{H}_{2}$-TPR profile of catalysts with different $\mathrm{Ru} / \mathrm{Fe}$ atomic ratios: (a) $\mathrm{Ru}_{1}-\mathrm{Fe}_{1} / \mathrm{SBA}-15$; (b) $\mathrm{Ru}_{2}-\mathrm{Fe}_{1} / \mathrm{SBA}-15$; (c) $\mathrm{Ru}_{10}-\mathrm{Fe}_{1} / \mathrm{SBA}-15$; (d) $\mathrm{Ru} /$ SBA-15; and (e) Fe/SBA-15; (f) SBA-15.

$\mathrm{Fe}^{2+}$ and $\mathrm{Fe}^{2+}$ to $\mathrm{Fe}^{0}$, respectively. ${ }^{31,32}$ The $\mathrm{Ru}-\mathrm{Fe}$ bimetallic samples demonstrated different $\mathrm{H}_{2}$-TPR behaviours compared with monometallic samples, depending on the $\mathrm{Ru} / \mathrm{Fe}$ atomic ratio. The introduction of non-noble metal with high valence has a negative effect on the ease of reducibility of noble metal oxide. ${ }^{33,34}$ When a small amount of Fe was added to form the $\mathrm{Ru}_{10}-\mathrm{Fe}_{1} / \mathrm{SBA}-15$ catalyst, the main peak of $\mathrm{H}_{2}$ consumption shifted to a slightly higher temperature with broadness compared with that in Ru/SBA-15. The increase in Fe amount in $\mathrm{Ru} / \mathrm{SBA}-15$ gradually shifted the $\mathrm{H}_{2}$ consumption peak toward higher temperatures. In contrast to the negative effect on the reduction of noble metal oxide caused by the addition of nonnoble metal, non-noble metal oxide was reduced at a lower temperature in the presence of a noble metal because of the easy activation of $\mathrm{H}_{2}$ molecules on noble metals. ${ }^{35}$ Therefore, a reasonable explanation was presented to address the peak broadening at certain $\mathrm{Ru} / \mathrm{Fe}$ atomic molar ratios of bimetallic catalysts, and an excessive amount of $\mathrm{Fe}$ in $\mathrm{Ru}_{1}-\mathrm{Fe}_{1} / \mathrm{SBA}-15$ led to a small peak at around $616 \mathrm{~K}$. The $\mathrm{H}_{2}$-TPR results demonstrate that particular interactions between $\mathrm{Ru}$ and Fe clearly occurred, and a portion of Fe species was reduced under the present conditions. 


\section{8. $\mathrm{H}_{2}$ chemisorption and AcOH-TPD}

$\mathrm{H}_{2}$-chemisorption and AcOH-TPD characterizations were applied to obtain more detailed information about the surface chemical properties of the catalysts. As shown in Table 4, SBA-5 was incapable of adsorbing $\mathrm{H}_{2}$ molecules chemically and the $\mathrm{Fe} /$ SBA-15 and Ru/SBA-15 displayed relatively poorer absorption of $\mathrm{H}_{2}$ than the $\mathrm{Ru}-\mathrm{Fe}$ bimetallic catalysts. Increasing contents of Fe in the bimetallic catalysts led to a declining amount of $\mathrm{H}_{2}$ adsorption, indicating that an excessive addition of $\mathrm{Fe}$ may have a negative effect on $\mathrm{H}_{2}$ activation.

The AcOH-TPD curve of the monometallic Fe/SBA-15 catalyst showed two peaks at 368 and $619 \mathrm{~K}$ (Fig. 5). The peak at the lower temperature may be due to the physically adsorbed species, and the peak at the higher temperature may be caused by the chemically adsorbed species. ${ }^{36}$ For SBA-15, only one peak at lower temperature of $368 \mathrm{~K}$ was observed. Similarly, only one peak attributed to physical adsorption appeared in the TPD spectrum of the monometallic Ru/SBA-15 catalyst. Thus, AcOH species were barely absorbed in Ru/SBA-15 or SBA-15 at the temperature performed the $\mathrm{AcOH}$ hydrogenolysis reaction (the reaction temperature was higher than $368 \mathrm{~K}$ ). However, the $\mathrm{Ru}-$ Fe bimetallic catalysts displayed a weak desorption peak at $619 \mathrm{~K}$ apart from the peak at $368 \mathrm{~K}$. The intensity of the peak assigned to chemical absorption increased with increasing Fe content. This observation suggests that some parts of Fe species dispersed on the bimetallic catalysts may act as adsorption sites for $\mathrm{AcOH}$.

\subsection{TEM}

High-resolution TEM (HRTEM) was used to investigate the inner interaction between $\mathrm{Ru}$ and $\mathrm{Fe}$ in the bimetallic catalysts at a sub-atomic scale. As shown in Fig. 6a, the HRTEM image of as-reduced $\mathrm{Ru}_{2}-\mathrm{Fe}_{1} / \mathrm{SBA}-15$ displayed a refined structure of nanoparticles. Intervals of 0.210 and $0.200 \mathrm{~nm}$ of the two typical lattice fringes were slightly less than the (002) and (101) lattice spacings in the classic structure of $\mathrm{Ru}$, but the two values were higher than the (110) and (200) lattice spacings of the classic

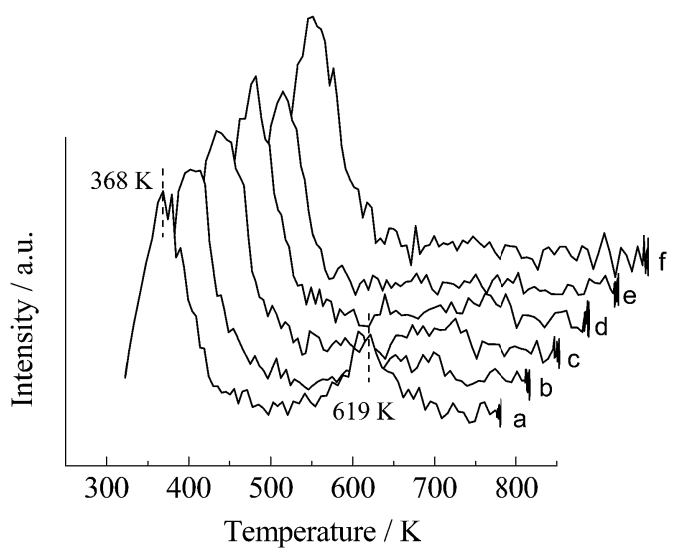

Fig. $5 \mathrm{AcOH}-\mathrm{TPD}$ result of as-reduced $5 \% \mathrm{Ru}_{x}-\mathrm{Fe}_{y} / \mathrm{SBA}-15$ catalysts: (a) Fe/SBA-15; (b) $\mathrm{Ru}_{1}-\mathrm{Fe}_{1} / \mathrm{SBA}-15$; (c) $\mathrm{Ru}_{2}-\mathrm{Fe}_{1} / \mathrm{SBA}-15$; (d) $\mathrm{Ru}_{10}-\mathrm{Fe}_{1} /$ SBA-15; and (e) Ru/SBA-15; (f) SBA-15.
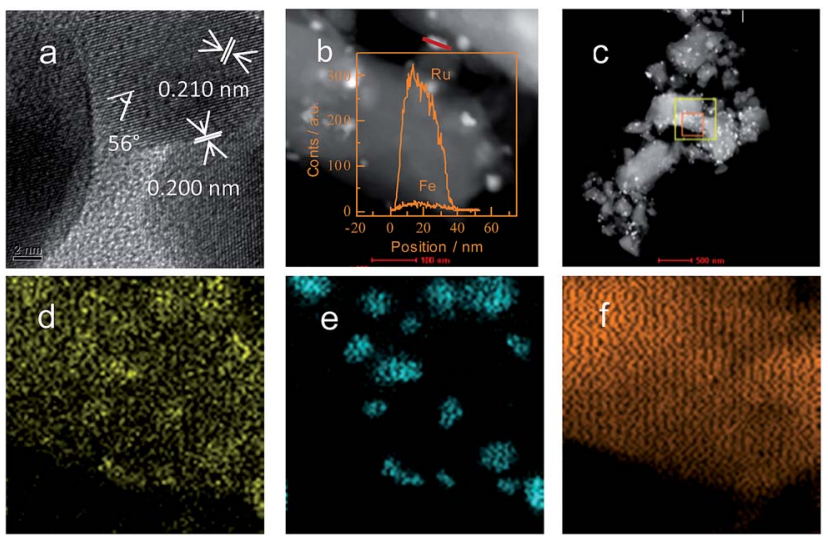

Fig. 6 STEM-EDX linear scanning pattern, elemental maps, and HRTEM image of $5 \% \mathrm{Ru}_{2}-\mathrm{Fe}_{1} / \mathrm{SBA}-15$ catalyst: (a) HRTEM image; (b) pattern of STEM-EDX linear scan; (c) dark-field image; (d) STEM-EDX elemental maps for Fe; (e) STEM-EDX elemental maps for Ru; and (f) STEM-EDX elemental maps for Si.

structure of $\mathrm{Fe}$, indicating the doping amount of $\mathrm{Fe}$ into metallic $\mathrm{Ru}$. The $56^{\circ}$ angle between the two inspected facets was lower than that between the (002) and (101) facets in the classic structure of $\mathrm{Ru}$, indicating the lattice distortion of $\mathrm{Ru}$ by doping the second element. The excellent overall dispersions of $\mathrm{Ru}$ and Fe particles were detected using STEM-EDX elemental linear scanning. When STEM-EDX elemental mapping was used to investigate the elemental dispersion at a larger scale (Fig. 6d-f), a portion of the Fe species was evenly dispersed on the surface of SBA-15, and the others coherently interacted with $\mathrm{Ru}$ domains. In the case of $\mathrm{Ru}_{2}-\mathrm{Fe}_{1} / \mathrm{SiO}_{2}$, a large average size of bimetallic particles with obvious inhomogeneity was observed (Fig. 5S, ESI $\dagger$ ).

\subsection{XPS}

XPS measurements of the $5 \% \mathrm{Ru}_{2}-\mathrm{Fe}_{1} / \mathrm{SBA}-15$ and $5 \% \mathrm{Fe} / \mathrm{SBA}$ 15 catalysts were performed to further investigate the elemental valence change in the catalysts. The Fe $2 \mathrm{p}$ and $\mathrm{Ru} 4 \mathrm{p}$ XPS data of the Fe/SBA-15 and $\mathrm{Ru}_{2}-\mathrm{Fe}_{1} / \mathrm{SBA}-15$ catalysts before and after reduction are displayed in Fig. 7 , and the deconvolution results are summarized in Table 5. The spectra of the as-calcined and as-reduced Fe/SBA-15 catalysts (Fig. 7a) were similar to each other. The main peak at $711.1 \mathrm{eV}$ and satellite peak at $718.8 \mathrm{eV}$ were attributed to $\mathrm{Fe}^{3+}\left(2 \mathrm{p}_{3 / 2}\right)$, indicating the presence of $\mathrm{Fe}^{3+}$. These results show that the Fe species on the Fe/SBA-15 catalyst were barely reduced under the present reduction conditions, which agreed with the previous results of $\mathrm{H}_{2}$-TPR. A peak at $711 \mathrm{eV}$ assigned to $\mathrm{Fe}^{3+}\left(2 \mathrm{p}_{3 / 2}\right)$ also appeared in the as-calcined $\mathrm{Ru}_{2}-\mathrm{Fe}_{1} / \mathrm{SBA}-15$ catalyst (Fig. 7b). The as-reduced $\mathrm{Ru}_{2}-\mathrm{Fe}_{1} / \mathrm{SBA}-$ 15 catalyst exhibited two new peaks distinct from the Fe species on Fe/SBA-15 compared with the as-calcined $\mathrm{Ru}_{2}-\mathrm{Fe}_{1} / \mathrm{SBA}-15$ catalyst. These peaks at 710.9 and $707.1 \mathrm{eV}$ were characteristic of $\mathrm{FeO}_{1+x}(0<x<0.5)$ and metallic $\mathrm{Fe}$, respectively. ${ }^{37-39}$ The concentration of metallic Fe species was estimated to be $10.2 \%$ after reduction. The $\mathrm{Ru}^{4+}$ species in $\mathrm{Ru}_{2}-\mathrm{Fe}_{1} / \mathrm{SBA}-15$ was reduced to metallic $\mathrm{Ru}$ at the present condition based on the 

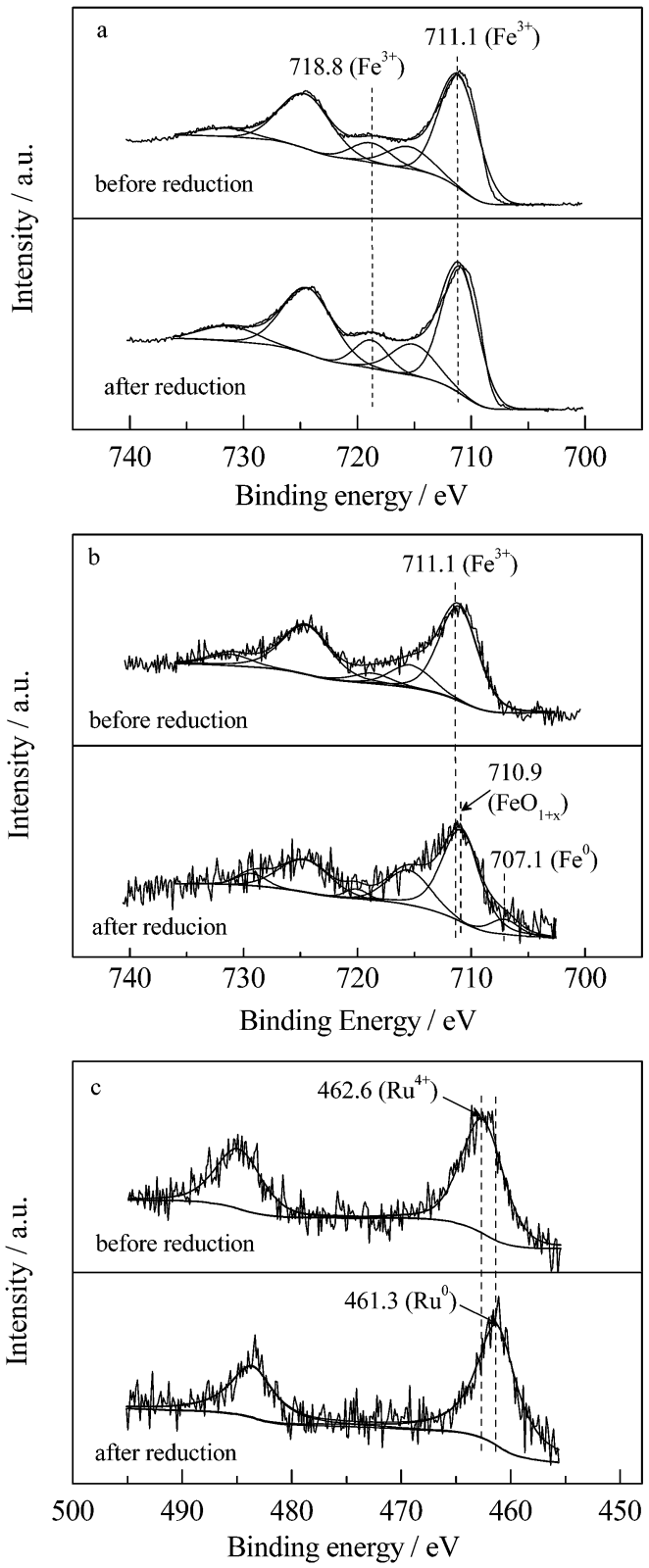

Fig. 7 Fe $2 p$ and Ru $4 p$ XPS of $5 \%$ Fe/SBA-15 and $5 \% \mathrm{Ru}_{2}-\mathrm{Fe}_{1} / \mathrm{SBA}-15$ catalysts before and after reduction: (a) Fe 2p spectra of Fe/SBA-15; (b) Fe $2 p$ spectra of $\mathrm{Ru}_{2}-\mathrm{Fe}_{1} / \mathrm{SBA}-15$; and (c) $\mathrm{Ru} 4 \mathrm{p}$ spectra of $\mathrm{Ru}_{2}-\mathrm{Fe}_{1} /$ SBA-15.

Table 5 Curve-fitting results of $\mathrm{Fe} 2 \mathrm{p}$ of $5 \% \mathrm{Fe} / \mathrm{SBA}-15$ and $5 \% \mathrm{Ru}_{2}-$ $\mathrm{Fe}_{1} / \mathrm{SBA}-15$ catalysts

\begin{tabular}{llccc}
\hline & & \multicolumn{2}{c}{ Concentration/\% } \\
\cline { 3 - 5 } Catalyst & Condition & $\mathrm{Fe}^{3+}$ & $\mathrm{FeO}_{1+x}{ }^{a}$ & Metallic Fe \\
\hline Fe/SBA-15 & As-calcined & 100 & 0 & 0 \\
& As-reduced & 100 & 0 & 0 \\
$\mathrm{Ru}_{2}-\mathrm{Fe}_{1} / \mathrm{SBA}-15$ & As-calcined & 100 & 0 & 0 \\
& As-reduced & 0 & 89.8 & 10.2 \\
${ }^{a} 0<x<0.5$. & & & &
\end{tabular}

shift from 462.6 to $461.3 \mathrm{eV}$ (Fig. 7c). This finding supports the previous notion based on $\mathrm{H}_{2}$-TPR results that some Fe species interacting with $\mathrm{Ru}$ were reduced to metallic $\mathrm{Fe}$, and others were in the form of $\mathrm{FeO}_{1+x}$ after reduction.

\subsection{Structure-performance correlation and possible catalytic mechanism}

The catalytic performance of the $5 \% \mathrm{Ru}_{x}-\mathrm{Fe}_{y} / \mathrm{SBA}-15$ catalysts, as well as the values of TOF, demonstrates that the addition of Fe considerably promoted $\mathrm{AcOH}$ conversion and EtOH selectivity. The consistent relation between the catalytic activity of the $5 \% \mathrm{Ru}_{x}-\mathrm{Fe}_{y} / \mathrm{SBA}-15$ catalysts and results of $\mathrm{H}_{2}$-chemisorption or ACOH-TPD shows that an appropriate ability to activate $\mathrm{H}_{2}$ molecules and adsorb AcOH molecules was likely the main reason for the increase in $\mathrm{AcOH}$ conversion and $\mathrm{EtOH}$ selectivity. Multiple characterizations, TEM, XPS, and $\mathrm{H}_{2}$-TPR could explain these phenomena, which are believed to be caused by the synergistic formation of $\mathrm{Ru}-\mathrm{Fe}$ bimetallic nanoparticles (parts of them in a form of Ru-Fe alloy) and existence of $\mathrm{Fe}$ oxide evenly dispersed on the catalyst surfaces. Since Fe catalyst alone showed very low activity for the hydrogenolysis of $\mathrm{AcOH}$ either even at higher temperatures, we believe that $\mathrm{H}_{2}$ molecule is activated by the nanoparticles of $\mathrm{Ru}$ and $\mathrm{Ru}-\mathrm{Fe}$, while the $\mathrm{Fe}$ species dispersed on catalysts are functioned to interact with $\mathrm{AcOH}$. However, the $\mathrm{H}$-species activated by $\mathrm{Ru}$ catalysts is so active that they are capable of breaking the $\mathrm{C}-\mathrm{O}$ bonds as well as the $\mathrm{C}-\mathrm{C}$ bonds, leading to the products mainly in the forms of over hydrogenated or cracked alkanes. In contrast, the $\mathrm{H}$ species activated by $\mathrm{Ru}-\mathrm{Fe}$ bimetallic nanoparticles shows capability of selectively breaking the $\mathrm{C}-\mathrm{O}$ bonds in carboxyl group and hydrogenating $\mathrm{C}=\mathrm{O}$ bonds but suppressing $\mathrm{C}-\mathrm{C}$ bond cleavage, resulting in a markedly enhanced selectivity toward the corresponding alcohol. As we learn from the characterization results above and in literature, ${ }^{34}$ the proportion of $\mathrm{Fe}$ species for the formation of Ru-Fe alloy are very limited under the present pre-treatment condition (pre-treated in $5 \%$ $\mathrm{H}_{2}-95 \% \mathrm{~N}_{2}$ flow at $623 \mathrm{~K}$ for $4 \mathrm{~h}$ ) and the rest of Fe species in oxide states are dispersed on the catalyst surfaces. Therefore, the catalysts containing Fe species only at an appropriate concentration may exhibit the highest catalytic performance at lower temperatures like $493 \mathrm{~K}$ (Table 1). In this case, the catalytic performance is strongly dependent of $\mathrm{Ru} / \mathrm{Fe}$ atomic ratio. Lower Fe addition brings about limited positive effects. While in the case of excess $\mathrm{Fe}$ addition like $5 \% \mathrm{Ru}_{1.5}-\mathrm{Fe}_{1} / \mathrm{SBA}-15$ and $5 \%$ $\mathrm{Ru}_{1}-\mathrm{Fe}_{1} / \mathrm{SBA}-15$ catalysts, the weakness of ability to create active and selective $\mathrm{H}$-species due to the excess of $\mathrm{Fe}$ may be the reason for the lower $\mathrm{AcOH}$ conversion. According to the present study, when the $\mathrm{Ru} / \mathrm{Fe}$ atomic ratio was optimized to be $2 / 1$, the $5 \% \mathrm{Ru}_{2}-\mathrm{Fe}_{1} / \mathrm{SBA}-15$ catalyst prepared by SDR method demonstrated the optimal performance in the $\mathrm{AcOH}$ hydrogenolysis to EtOH. At an elevated temperature like at $533 \mathrm{~K}$, the catalysts doped with $\mathrm{Fe}$ with $\mathrm{Ru} / \mathrm{Fe}$ ratios from 15/1 to 2/1 can give $\mathrm{AcOH}$ conversion approaching to over $90 \%$ (Table S2, ESI $\dagger$ ) due to the acceleration of mass transfer at higher reaction temperatures (Fig. 1). This is particularly the case for the catalysts of 
$\mathrm{Ru}_{10}-\mathrm{Fe}_{1} / \mathrm{SBA}-15, \mathrm{Ru}_{3}-\mathrm{Fe}_{1} / \mathrm{SBA}-15$ and $\mathrm{Ru}_{2}-\mathrm{Fe}_{1} / \mathrm{SBA}-15$; they give limited differences in performance at $533 \mathrm{~K}$ (Table S2, ESI $\dagger$ ).

Considering the different performances and structures of the catalysts prepared by SDR and impregnation methods, the functional $-\mathrm{NH}_{2}$ groups had an important function in controlling the final composition and structure of the catalysts. Moreover, the $5 \% \mathrm{Ru}_{2}-\mathrm{Fe}_{1} / \mathrm{SBA}-15-\mathrm{CoIm}-573 \mathrm{~K}$ catalyst with smaller bimetallic particle size presents high activity for the $\mathrm{C}-\mathrm{C}$ bond cleavage with poor selectivity to $\mathrm{EtOH}$ production, while the $5 \% \mathrm{Ru}_{2}-\mathrm{Fe}_{1} / \mathrm{SBA}-15-\mathrm{CoIm}-773 \mathrm{~K}$ catalyst with larger bimetallic particle sizes shows poor activity. Further, the $\mathrm{Ru}_{2}-$ $\mathrm{Fe}_{1} / \mathrm{SiO}_{2}$ catalyst showed lower activity and selectivity, although the exact reason for the result remains unclear. However, the larger average size of bimetallic particles with obvious inhomogeneity and lack of uniform channels in $5 \% \mathrm{Ru}_{2}-\mathrm{Fe}_{1} / \mathrm{SiO}_{2}$ compared with those in SBA-15-supported counterpart could not be excluded. Moreover, the surface acidity of the catalysts is believed to have an obvious effect on the selectivity to products. The decrease in $\mathrm{Si} / \mathrm{Al}$ ratio of aluminosilicate zeolites of ZSM-5 and HY could bring about an increase in selectivity to EtOAc, which most probably is due to the increment of acidity. ${ }^{40}$ The results demonstrate that the hydrogenolysis of carboxylic acids to corresponding alcohols is a structure-sensitive reaction.

Rachmady and Chen have reported that acyl species is a predominant reaction intermediate which can be hydrogenated to aldehydes and further to alcohols in the process of hydrogenolysis of carboxylic acids. ${ }^{\mathbf{1 7 4 1}}$ Combined with the results of hydrogenolysis of several carboxylic acids, a designed mechanism describing the possible pathway for the reaction is shown in Fig. 8. Taking the AcOH hydrogenolysis reaction as an example ( $\mathrm{R}$ - set as $\mathrm{CH}_{3}$ - in Fig. 8), the route of AcOH hydrogenolysis to EtOH proceeds by $\mathrm{C}-\mathrm{O}$ bond cleavage in $\mathrm{AcOH}$ to form $\mathrm{CH}_{3} \mathrm{CO}$ species, subsequently the hydrogenation of $\mathrm{CH}_{3} \mathrm{CO}$ species to $\mathrm{AH}$ and further hydrogenation to EtOH. ${ }^{\mathbf{1 7 , 4 1}}$ However, $\mathrm{C}-\mathrm{C}$ cleavage at the first step is possible, which leads to the formation of $\mathrm{CH}_{4}$. A significant amount of $\mathrm{CH}_{4}$ was produced over $5 \% \mathrm{Ru} / \mathrm{SBA}-15$ because of the excellent capacity

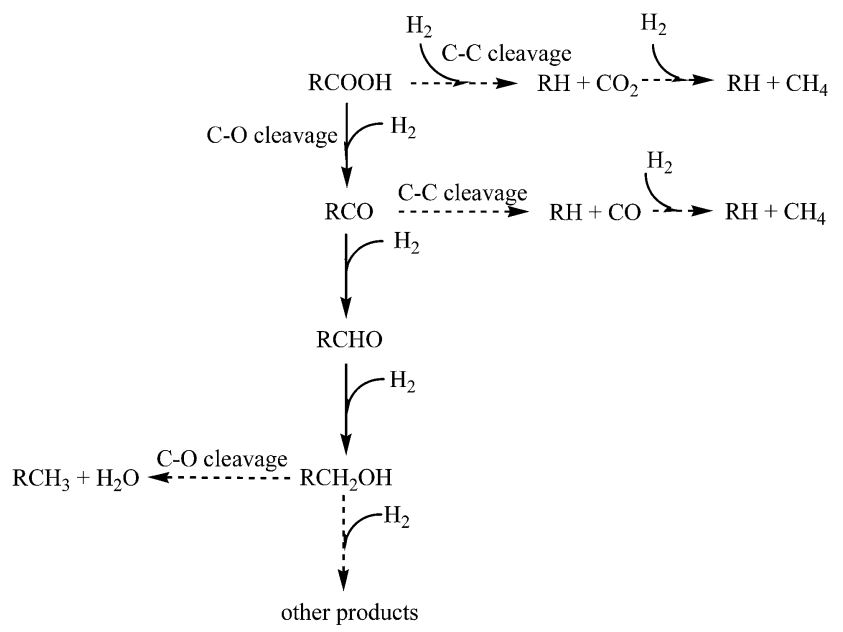

Fig. 8 Schematic of reactions involved in the conversion of carboxylic acid based on the detected products. of monometallic $\mathrm{Ru}$ for cleaving $\mathrm{C}-\mathrm{C}$ bond. In contrast, the $\mathrm{Ru}-$ Fe bimetallic catalysts restricted the occurrence of $\mathrm{C}-\mathrm{C}$ cleavage, thereby reducing the formation of $\mathrm{CH}_{4}$. The portion of Fe species dispersed on SBA-15 was suspected to interact with $\mathrm{AcOH}$, as shown by AcOH-TPD. The increasing concentration of $\mathrm{AcOH}$ on the surface of the catalyst forced the conversion of $\mathrm{AcOH}$. Therefore, the introduction of Fe benefited the hydrogenolysis of $\mathrm{AcOH}$ in two aspects. $\mathrm{AH}$ was partly produced by hydrogenolysis of $\mathrm{AcOH}$, so a significant amount of $\mathrm{AH}$ was detected at relatively low reaction temperature. For instance, the selectivity to $\mathrm{AH}$ reached $20.3 \%$ using $5 \% \mathrm{Ru}_{2}-\mathrm{Fe}_{1} / \mathrm{SBA}-15$ at $493 \mathrm{~K}$ (Fig. 1). AH is highly active and can easily be hydrogenated to EtOH or transformed to EtOAc through self-redox, as shown in the decrease in selectivity of $\mathrm{AH}$ to $2.4 \%$ at $533 \mathrm{~K}$. The route to EtOAc leads to the decreased selectivity to EtOH. The phenomena of cleaving $\mathrm{C}-\mathrm{C}$ and $\mathrm{C}-\mathrm{O}$ of EtOH are also possibly present during the reaction, leading to the formation of $\mathrm{CH}_{4}$ and $\mathrm{C}_{2} \mathrm{H}_{6}$. By controlling the experimental conditions, EtOH was cleaved into $\mathrm{CH}_{4}$ with selectivity above $90 \%$ on $5 \%$ $\mathrm{Ru} / \mathrm{SBA}-15$, but the selectivities to $\mathrm{CH}_{4}$ and $\mathrm{C}_{2} \mathrm{H}_{6}$ were equally split on $5 \% \mathrm{Ru}_{2}-\mathrm{Fe}_{1} / \mathrm{SBA}-15$ (Fig. $6 \mathrm{~S}$, ESI $\dagger$ ). This result suggests that the introduction of $\mathrm{Fe}$ was advantageous in reducing $\mathrm{C}-\mathrm{C}$ cleavage.

\section{Conclusions}

In this work, the results of multiple characterizations and catalytic tests show that the introduction of Fe had remarkable effects on the structure and performance of Ru-based supported catalysts. A portion of Fe species interacted with $\mathrm{Ru}$ in alloy form, and the other portion dispersed evenly onto SBA-15 at an oxidation state. Fe oxide had an important function in the absorption of $\mathrm{AcOH}$, and $\mathrm{Ru}-\mathrm{Fe}$ bimetallic nanoparticles exhibited good capacity for activating $\mathrm{H}_{2}$ to reduce $\mathrm{AcOH}$ into EtOH. Thus, the Ru-Fe bimetallic catalysts achieved high selectivity toward EtOH by hydrogenolysis of $\mathrm{AcOH}$ compared with the monometallic catalysts. Nearly $100 \% \mathrm{AcOH}$ conversion and $88 \%$ EtOH selectivity were achieved by the optimal $\mathrm{Ru}-\mathrm{Fe} /$ SBA-15 catalyst at an atomic ratio of $2 / 1$ under mild conditions. The $\mathrm{Ru}_{2}-\mathrm{Fe}_{1} / \mathrm{SBA}-15$ catalyst was highly stable such that high catalytic activity in AcOH hydrogenolysis was maintained over $300 \mathrm{~h}$.

\section{Experimental}

\subsection{Chemicals}

Chemicals with analytical or guaranteed purities, such as $\mathrm{AcOH}$, propionic acid, levulinic acid, butyric acid, lactic acid, 1,4dioxane, EtOH, $\mathrm{RuCl}_{3} \cdot \mathrm{H}_{2} \mathrm{O}$, and $\mathrm{Fe}\left(\mathrm{NO}_{3}\right)_{3} \cdot 9 \mathrm{H}_{2} \mathrm{O}$, were purchased from China Pharmaceutical Group Shanghai Chemical Reagent Co., Ltd. $\mathrm{SiO}_{2}$ was purchased from Qingdao Fine Chemical Co., Ltd. Amphiphilic triblock copolymer $(\mathrm{EO})_{20}(\mathrm{PO})_{70}(\mathrm{EO})_{20}(\mathrm{P} 123)$, tetraethyl orthosilicate (TEOS), and 3-aminopropyltriethoxysilane (APTES) were purchased from Sigma-Aldrich. Hydrogen and nitrogen were purchased from Linde Industrial Gases. All the reagents were used as received. 


\subsection{Catalyst preparation}

Ordered hexagonal mesoporous silica SBA-15 was synthesized using P123 as the structure-directing agent and TEOS as the silica source according to the detailed procedure in the published literature. ${ }^{42}$ SBA-15 was functionalized by APTES using the following procedure. Approximately $2.0 \mathrm{~g}$ of SBA-15 was suspended in $100 \mathrm{~mL}$ of EtOH in a round bottom flask and $5.0 \mathrm{~g}$ of APTES was added dropwise. The suspension was refluxed at $363 \mathrm{~K}$ for $24 \mathrm{~h}$. Finally, the slurry was filtered, and the solid was washed with EtOH and dried at $333 \mathrm{~K}$ overnight. The solid obtained was denoted as $\mathrm{NH}_{2}-\mathrm{SBA}-15$.

SBA-15-supported Ru-Fe catalysts were prepared by the SDR method according to a similar procedure reported elsewhere, ${ }^{\mathbf{4 3}}$ which involves two steps, namely, impregnation and reduction. First, $0.1250 \mathrm{~g}$ of $\mathrm{RuCl}_{3} \cdot n \mathrm{H}_{2} \mathrm{O}$ was dissolved in $50 \mathrm{~mL}$ of distilled water, and the solution was poured into a beaker containing $1.0 \mathrm{~g}$ of $\mathrm{NH}_{2}-\mathrm{SBA}-15$ with vigorous stirring. Then, $20 \mathrm{~mL}$ of $\mathrm{NaBH}_{4}$ aqueous solution $\left(0.079 \mathrm{~mol} \mathrm{~L}^{-1}\right)$ was added dropwise into the suspension. After $15 \mathrm{~min}$, the mixture was filtered and the solid was washed with distilled water for at least eight times to obtain $\mathrm{Ru} / \mathrm{NH}_{2}-\mathrm{SBA}-15$. After that, a certain amount of $\mathrm{Fe}\left(\mathrm{NO}_{3}\right)_{3} \cdot 9 \mathrm{H}_{2} \mathrm{O}$ was dissolved in $50 \mathrm{~mL}$ of distilled water, and $\mathrm{Ru} / \mathrm{NH}_{2}-\mathrm{SBA}-15$ was re-dispersed in the solution. After the mixture was added dropwise with $\mathrm{NaBH}_{4}$ aqueous solution under vigorous stirring for $1 \mathrm{~h}$, the solid was collected by filtration, washing, drying, and calcination at $773 \mathrm{~K}$ for $6 \mathrm{~h}$. The solid was labeled as $5 \% \mathrm{Ru}_{x}-\mathrm{Fe}_{y} / \mathrm{SBA}-15$. To investigate the influence of additional Fe on the catalytic performance, the $\mathrm{Ru}$ loading amount was fixed at $5 \mathrm{wt} \%$, and $x / y$ represented the $\mathrm{Ru} /$ Fe atomic ratio. Monometallic Ru/SBA-15 and Fe/SBA-15 catalysts were prepared using the aforementioned SRD method with $0.1250 \mathrm{~g} \mathrm{RuCl} \cdot n \mathrm{H}_{2} \mathrm{O}$ and $3.607 \mathrm{~g} \mathrm{Fe}\left(\mathrm{NO}_{3}\right)_{3} \cdot 9 \mathrm{H}_{2} \mathrm{O}$, respectively. In addition, the catalysts with $\mathrm{Ru} / \mathrm{Fe}$ atomic ratio set to $2 / 1$ were prepared according to the SDR method by replacing SBA- 15 with different supports $\left(\mathrm{SiO}_{2}, \mathrm{ZSM}-5\right.$ with different $\mathrm{Si} / \mathrm{Al}$ ratio for 25 and $50, \mathrm{HY}(\mathrm{Si} / \mathrm{Al}=30)$, and $\left.\mathrm{Al}_{2} \mathrm{O}_{3}\right)$. The catalysts were denoted as $5 \% \mathrm{Ru}_{2}-\mathrm{Fe}_{1} / \mathrm{SiO}_{2}, \quad 5 \% \mathrm{Ru}_{2}-\mathrm{Fe}_{1} / \mathrm{ZSM}-5 \quad(\mathrm{Si} / \mathrm{Al}=50), \quad 5 \%$ $\mathrm{Ru}_{2}-\mathrm{Fe}_{1} / \mathrm{ZSM}-5$ ( $\left.\mathrm{Si} / \mathrm{Al}=25\right), 5 \% \mathrm{Ru}_{2}-\mathrm{Fe}_{1} / \mathrm{HY}(\mathrm{Si} / \mathrm{Al}=30), 5 \%$ $\mathrm{Ru}_{2}-\mathrm{Fe}_{1} / \mathrm{Al}_{2} \mathrm{O}_{3}$.

The catalysts labelled as $5 \% \mathrm{Ru}_{2}-\mathrm{Fe}_{1} / \mathrm{SBA}-15-\mathrm{CoIm}-T$ were prepared for comparison following the procedures described below. First, $1.0 \mathrm{~g}$ of non-functionalized SBA-15 was dispersed in $50 \mathrm{~mL}$ of acetone solution of $\mathrm{RuCl}_{3} \cdot n \mathrm{H}_{2} \mathrm{O}$ and $\mathrm{Fe}\left(\mathrm{NO}_{3}\right)_{3} \cdot 9 \mathrm{H}_{2} \mathrm{O}$, and the obtained suspension was stirred at room temperature for $12 \mathrm{~h}$. The solvent was evaporated and the solid was dried at $333 \mathrm{~K}$. The solid was calcined at 573 and $773 \mathrm{~K}$ for $4 \mathrm{~h}$ each, and the obtained catalysts were labeled as $5 \% \mathrm{Ru}_{2}-$ $\mathrm{Fe}_{1} / \mathrm{SBA}-15-\mathrm{CoIm}-573 \mathrm{~K}$ and $5 \% \mathrm{Ru}_{2}-\mathrm{Fe}_{1} / \mathrm{SBA}-15-\mathrm{CoIm}-773 \mathrm{~K}$, respectively.

\subsection{Catalyst evaluation}

The hydrogenolysis of carboxylic acids, such as $\mathrm{AcOH}$, propionic acid, levulinic acid, and butyric acid, was conducted in a stainless tubular fixed-bed reactor equipped with a computercontrolled auto-sampling system. For the hydrogenolysis of levulinic acid, $10 \mathrm{wt} \%$ levulinic acid/1,4-dioxane solution was prepared. Typically, $0.2 \mathrm{~g}$ of as-prepared catalyst was loaded into a glass tube. The catalyst was pretreated in $5 \% \mathrm{H}_{2}-95 \% \mathrm{~N}_{2}$ flow $\left(50 \mathrm{~mL} \mathrm{~min}{ }^{-1}\right)$ at $623 \mathrm{~K}$ for $4 \mathrm{~h}$, with a heating rate of $2 \mathrm{~K} \mathrm{~min}^{-1}$. The temperature was decreased to the target reaction temperature, and pure $\mathrm{H}_{2}$ was introduced into the reactor. The reaction system pressure was precisely controlled by a back-pressure valve to 3.0 $\mathrm{MPa}$ (in the case of levulinic acid hydrogenolysis, a pressure of $0.75 \mathrm{MPa}$ was also employed). Carboxylic acid was pumped into the reactor using a Series III digital high-performance liquid chromatography (HPLC) pump (Scientific Systems, Inc.). The outlet stream was injected into a gas chromatograph (GC) equipped with a flame ionization detector and KB-Wax capillary column $(30 \mathrm{~m} \times 0.32 \mathrm{~mm} \times 0.33 \mu \mathrm{m})$ to detect oxygenates. The products in gas phase were auto-sampled into another GC equipped with a thermal conductivity detector and dual columns, Gaskuropack 54 column $(3 \mathrm{~m})$ and active carbon column $(2 \mathrm{~m})$, to quantify $\mathrm{CH}_{4}, \mathrm{CO}_{2}, \mathrm{CO}$, and $\mathrm{C}_{2} \mathrm{H}_{6}$. The conversion and product selectivity were calculated using the calibrated area normalization method.

The hydrogenolysis of lactic acid was performed in a steel autoclave with a volume of $50 \mathrm{~mL}$ using a magnetic stirrer. The reactor was pressurized three times with $1.0 \mathrm{MPa} \mathrm{H}_{2}(99.995 \%)$ after placing $10 \mathrm{~mL}$ of $5 \%$ lactic acid aqueous solution and $0.1 \mathrm{~g}$ of $5 \% \mathrm{Ru}_{2}-\mathrm{Fe}_{1} / \mathrm{SBA}-15$ in the autoclave. The autoclave was pressurized with the same gas at the desired pressure, and heated to $473 \mathrm{~K}$. After the reaction, the autoclave was cooled to room temperature in a water bath and decompressed. Finally, the liquids and catalysts were separated by decantation. The solution was analysed by HPLC equipped with a refractive index detector and a UV-Vis detector.

\subsection{Catalyst characterization}

The $\mathrm{Ru}$ and Fe loadings on the catalysts were measured by a S8TIGER XRF spectrometer. Approximately $0.2 \mathrm{~g}$ of catalyst and $0.8 \mathrm{~g}$ of boric acid were mixed well and compressed to tablets (36 $\mathrm{mm}$ diameter and $2 \mathrm{~mm}$ thickness). The spectrum was recorded at room temperature.

$\mathrm{N}_{2}$ adsorption-desorption isotherms were measured at 77.3 K using a Micromeritics TriStar II 3020 porosimetry analyzer. Prior to adsorption, the sample was degassed under vacuum at $473 \mathrm{~K}$ for $2 \mathrm{~h}$. The specific surface area was calculated based on the Brunauer-Emmett-Teller method. According to the Barrett-Joyner-Halenda method, the average pore diameter and pore size distributions were evaluated from the desorption branch of the isotherms.

$\mathrm{H}_{2}$-TPR was performed in a Micromeritics AutoChem II 2920 Chemisorption Analyzer. Samples $(0.1 \mathrm{~g})$ were weighed, flushed with $50 \mathrm{~mL} \mathrm{~min}^{-1}$ high purity $\mathrm{He}$ at $473 \mathrm{~K}$ for $1 \mathrm{~h}$, and cooled to $323 \mathrm{~K}$. Subsequently, $5 \% \mathrm{H}_{2}-95 \%$ Ar flowed through the sample while the temperature increased from 323 to $900 \mathrm{~K}$ at a rate of $10 \mathrm{~K} \mathrm{~min}^{-1}$. Mass spectrometer signals of $\mathrm{m} / z=2$ were recorded to detect $\mathrm{H}_{2}$ consumption.

Static $\mathrm{H}_{2}$ chemisorption was measured by a Micromeritics ASAP $2020(\mathrm{M}+\mathrm{C})$ apparatus. The catalyst was pre-reduced by $5 \% \mathrm{H}_{2}-95 \% \mathrm{~N}_{2}$ flow as the temperature increased from 303 to $623 \mathrm{~K}$ at a rate of $2 \mathrm{~K} \mathrm{~min}^{-1}$ in the pipe furnace. The pre-reduced 
catalyst was transferred into a quartz test tube in the apparatus, soaked in $\mathrm{H}_{2}$ at $623 \mathrm{~K}$ for $15 \mathrm{~min}$, evacuated for $60 \mathrm{~min}$, and then cooled to $308 \mathrm{~K}$. After pretreatment, the catalysts were characterized using a standard program.

AcOH-TPD was performed in a Micromeritics AutoChem II 2920 Chemisorption Analyzer. Approximately $0.2 \mathrm{~g}$ of the asreduced catalyst was sealed in a desiccator, which was full of $\mathrm{AcOH}$ vapor for $24 \mathrm{~h}$. The catalyst was loaded into a U-type tube in the analyzer, and swept by Ar as the temperature increased from 323 to $773 \mathrm{~K}$ at a rate of $10 \mathrm{~K} \mathrm{~min}^{-1}$. The desorbed $\mathrm{AcOH}$ molecules were detected by a Hiden Qic-20 mass spectrometer with the signals of $m / z=45$ and $m / z=43$.

XRD patterns were determined using a Philips PANalytical X'pert PRO diffractometer with a graphite monochrometer and $\mathrm{Cu} \mathrm{K} \alpha$ radiation ( $40 \mathrm{kV}$ and $30 \mathrm{~mA}$ ), and a scanning range from 20 to $90^{\circ}$. According to the Scherrer equation, the particle size of catalysts was calculated using the most intense peak $\left(2 \theta=44.0^{\circ}\right)$.

TEM images were taken on a Philips Analytical FEI Tecnai 30 electron microscope operated at an acceleration voltage of $300 \mathrm{~V}$. The sample powder was highly dispersed in EtOH at room temperature, and dropped into copper grids for observation.

XPS measurement was conducted on a PHI QUANTUM 2000 Scanning ESCA Microprobe instrument using an $\mathrm{Al} \mathrm{K} \alpha$ radiation source $(h v=1486.6 \mathrm{eV})$. The XPS spectra of the as-reduced catalysts and as-calcined catalysts were recorded, and the binding energy (BE) was calibrated according to the $\mathrm{BE}$ of $\mathrm{C}_{1 \mathrm{~s}}$ $(284.6 \mathrm{eV})$.

\section{Acknowledgements}

We acknowledge the financial supports from the MOST of China (2011CBA00508), the NSFC (20923004, 21173175, and 21303141), the Research Fund for the Doctoral Program of Higher Education (20110121130002), and the Program for Changjiang Scholars and Innovative Research Team in University (IRT1036).

\section{Notes and references}

1 Y. Lin and S. Tanaka, Appl. Microbiol. Biotechnol., 2006, 69, 627-642.

2 M. T. Holtzapple and C. B. Granda, Appl. Biochem. Biotechnol., 2009, 156, 525-536.

3 H. N. Chang, N.-J. Kim, J. W. Kang and C. M. Jeong, Biotechnol. Bioprocess Eng., 2010, 15, 1-10.

4 V. Pham, M. Holtzapple and M. El-Halwagi, J. Ind. Microbiol. Biotechnol., 2010, 37, 1157-1168.

5 J. J. Spivey and A. Egbebi, Chem. Soc. Rev., 2007, 36, 15141528.

6 R. Ooms, M. Dusselier, J. A. Geboers, B. O. de Beeck, R. Verhaeven, E. Gobechiya, J. A. Martens, A. Redl and B. F. Sels, Green Chem., 2014, 16, 695-707.

7 A. Corma, S. Iborra and A. Velty, Chem. Rev., 2007, 107, 24112502.

8 T. Eggeman, D. Verser and E. Weber, in An Indirect Route for Ethanol Production, US Department of Energy: ZeaChem Inc., 2005, DE-FG36-03GO13010.
9 Y. Nakagawa and K. Tomishige, Catal. Surv. Asia, 2011, 15, 111-116.

10 S. Harnos, G. Onyestyák and J. Valyon, Appl. Catal., A, 2012, 439, 31-40.

11 J. J. Bozell, L. Moens, D. C. Elliott, Y. Wang, G. G. Neuenscwander, S. W. Fitzpatrick, R. J. Bilski and J. L. Jarnefeld, Resour., Conserv. Recycl., 2000, 28, 227-239.

12 E. Uccani, in Heterogeneous Catalysis and Fine Chemicals, ed. M. Guisnet, J. Barrault, C. Bouchoule, D. Duprez, C. Montassier and G. Pérot, Elsevier, Amsterdam, 1988, p. 33.

13 L. M. He, H. Y. Cheng, G. F. Liang, Y. C. Yu and F. Y. Zhao, Appl. Catal., A, 2013, 452, 88-93.

14 L. H. Tan Tai and V. Nardello-Rataj, in Handbook of Detergents Part E: Applications, ed. U. Zoller, CRC press, Taylor and Francis group, Boca Raton, 2009, p. 110.

15 J. L. Hargrove, P. Greenspan and D. K. Hartle, Exp. Biol. Med., 2004, 229, 215-226.

16 W. Rachmady and M. A. Vannice, J. Catal., 2000, 192, 322334.

17 W. Rachmady and M. A. Vannice, J. Catal., 2002, 207, 317-330.

18 G. Onyestyák, S. Harnos, S. Klébert, M. Štolcová, A. Kaszonyi and D. Kalló, Appl. Catal., A, 2013, 464, 313-321.

19 J. ten Dam and U. Hanefeld, ChemSusChem, 2011, 4, 10171034.

20 C. Luo, S. Wang and H. C. Liu, Angew. Chem., Int. Ed., 2007, 46, 7636-7639.

21 H. J. Wan, R. V. Chaudhari and B. Subramaniam, Energy Fuels, 2012, 27, 487-493.

22 T. Jiang, Y. X. Zhou, S. G. Liang, H. Z. Liu and B. X. Han, Green Chem., 2009, 11, 1000-1006.

23 T. Miyake, T. Makino, S.-i. Taniguchi, H. Watanuki, T. Niki, S. Shimizu, Y. Kojima and M. Sano, Appl. Catal., A, 2009, 364, 108-112.

24 M. Toba, S.-i. Tanaka, S.-i. Niwa, F. Mizukami, Z. Koppány, L. Guczi, K.-Y. Cheah and T.-S. Tang, Appl. Catal., A, 1999, 189, 243-250.

25 Y. M. Liu, Y. Cao, N. Yi, W. L. Feng, W. L. Dai, S. R. Yan, H. Y. He and K. N. Fan, J. Catal., 2004, 224, 417-428.

26 A. Sampieri, S. Pronier, J. Blanchard, M. Breysse, S. Brunet, K. Fajerwerg, C. Louis and G. Pérot, Catal. Today, 2005, 107, 537-544.

27 A. Martínez, C. López, F. Márquez and I. Díaz, J. Catal., 2003, 220, 486-499.

28 J. W. Zheng, H. Q. Lin, Y. N. Wang, X. L. Zheng, X. P. Duan and Y. Z. Yuan, J. Catal., 2013, 297, 110-118.

29 H. Olcay, L. J. Xu, Y. Xu and G. W. Huber, ChemCatChem, 2010, 2, 1420-1424.

30 J. L. Li, Y. H. Zhang, Y. X. Zhao, K. Y. Liew and J. P. Hong, Catal. Sci. Technol., 2014, 4, 1005-1011.

31 R. M. M. Abbaslou, A. Tavassoli, J. Soltan and A. K. Dalai, Appl. Catal., A, 2009, 367, 47-52.

32 F. J. Berry, L. W. Lin, C. Y. Wang, R. Y. Tang, S. Zhang and D. B. Liang, J. Chem. Soc., Faraday Trans. 1, 1985, 81, 22932305.

33 R. Burch and M. J. Hayes, J. Catal., 1997, 165, 249-261.

34 B. D. Li, J. Wang, Y. Z. Yuan, H. Ariga, S. Takakusagi and K. Asakura, ACS Catal., 2011, 1, 1521-1528. 
35 A. Guerrero-Ruiz, A. Sepúlveda-Escribano and I. RodriguezRamos, Appl. Catal., A, 1992, 81, 81-100.

36 J. Fung and I. Wang, Appl. Catal., A, 1998, 166, 327-334.

37 C. R. Brundle, T. J. Chuang and K. Wandelt, Surf. Sci., 1977, 68, 459-468.

38 N. S. McIntyre and D. G. Zetaruk, Anal. Chem., 1977, 49, 1521-1529.

39 V. Schünemann, H. Trevino, W. M. H. Sachtler, K. Fogash and J. A. Dumesic, J. Phys. Chem., 1995, 99, 1317-1321.
40 L. Shirazi, E. Jamshidi and M. R. Ghasemi, Cryst. Res. Technol., 2008, 43, 1300-1306.

41 L. G. Chen, Y. P. Li, X. H. Zhang, Q. Zhang, T. J. Wang and L. L. Ma, Appl. Catal., A, 2014, 478, 117-128.

42 D. Y. Zhao, Q. S. Huo, J. L. Feng, B. F. Chmelka and G. D. Stucky, J. Am. Chem. Soc., 1998, 120, 6024-6036.

43 Y. N. Wang, X. P. Duan, J. W. Zheng, H. Q. Lin, Y. Z. Yuan, H. Ariga, S. Takakusagi and K. Asakura, Catal. Sci. Technol., 2012, 2, 1637-1639. 